\title{
No pharmacodynamic (PD) and pharmacokinetic (PK) interaction of riociguat (BAY 63-2521) and aspirin
}

\author{
Reiner Frey ${ }^{1 *}$, Wolfgang Mück', Sigrun Unger ${ }^{2}$, Michael Reber ${ }^{1}$, Jörn Krätzschmar ${ }^{1}$, Corina Becker ${ }^{1}$, Georg Wensing ${ }^{1}$ \\ From 5th International Conference on cGMP: Generators, Effectors and Therapeutic Implications \\ Halle, Germany. 24-26 June 2011
}

\section{Objectives}

Riociguat, an oral soluble guanylate cyclase (sGC) stimulator, is a new candidate for treatment of pulmonary hypertension (PH). Riociguat increases cGMP production through a novel dual mode of action: direct NOindependent stimulation of sGC and increasing sensitivity of sGC to low levels of NO. Another sGC stimulator, BAY 41-2272, has shown anti-platelet activity in animal models, as have BAY 41-2272 and riociguat in washed human platelets, although bleeding has not been noted as an adverse event (AE) in riociguat clinical studies $[1,2]$. As riociguat and aspirin are likely to be used together in $\mathrm{PH}$, it was of interest to investigate potential $\mathrm{PD}$ and $\mathrm{PK}$ interactions.

\section{Methods}

In this randomized, open-label, crossover study, participants took $2.5 \mathrm{mg} /$ day riociguat, two morning doses of $500 \mathrm{mg}$ aspirin, or both drugs concomitantly.

\section{Results}

Eighteen healthy men were enrolled. Six of 17 participants in the safety evaluation reported $\geq 1$ treatmentemergent AE. All AEs were mild except 1 case of moderate headache following riociguat administration. Fifteen participants were valid for $\mathrm{PD} / \mathrm{PK}$ analysis. Riociguat PK values were independent of aspirin coadministration. One hour after coadministration of riociguat and aspirin, the mean increase in fraction unbound was $19 \%$ for riociguat and $24 \%$ for its metabolite M-1 (BAY 60-4552) indicating mild displacement by salicylic acid, the main aspirin metabolite. Effects of aspirin on bleeding time, platelet aggregation and plasma thromboxane $B_{2}$ were not affected by concomitant riociguat. Riociguat alone had no effect on PD variables.

\section{Conclusion}

Riociguat demonstrated no clinically relevant PD or PK interaction with aspirin. Coadministration of riociguat and aspirin does not require dose adjustment. Phase 3 randomized controlled trials are investigating riociguat in chronic thromboembolic pulmonary hypertension or pulmonary arterial hypertension.

\section{Author details \\ ${ }^{1}$ Clinical Pharmacology, Bayer HealthCare AG, Pharma Research Center, Wuppertal, Germany. ${ }^{2}$ Global Biostatistics, Bayer HealthCare AG, Pharma Research Center, Wuppertal, Germany.}

Published: 1 August 2011

\section{References}

1. Roger S, Badier-Commander C, Paysant J, Cordi A, Verbeuren TJ, Félétou M: The anti-aggregating effect of BAY 41-2272, a stimulator of soluble guanylyl cyclase, requires the presence of nitric oxide. Br J Pharmacol 2010, 161:1044-1058.

2. Ghofrani HA, Hoeper MM, Halank M, Meyer FJ, Staehler G, Behr J, Ewert R, Weimann G, Grimminger F: Riociguat for chronic thromboembolic pulmonary hypertension and pulmonary arterial hypertension: a phase II study. Eur Respir J 2010, 36:792-799.

\section{doi:10.1186/1471-2210-11-S1-P25}

Cite this article as: Frey et al:: No pharmacodynamic (PD) and pharmacokinetic (PK) interaction of riociguat (BAY 63-2521) and aspirin. BMC Pharmacology 2011 11(Suppl 1):P25.

\footnotetext{
* Correspondence: reiner.frey@bayer.com

${ }^{1}$ Clinical Pharmacology, Bayer HealthCare AG, Pharma Research Center,

Wuppertal, Germany

Full list of author information is available at the end of the article
}

(c) 2011 Frey et al; licensee BioMed Central Ltd. This is an open access article distributed under the terms of the Creative Commons Attribution License (http://creativecommons.org/licenses/by/2.0), which permits unrestricted use, distribution, and reproduction in any medium, provided the original work is properly cited. 